\title{
Investigation of saline water intrusions into the Curonian Lagoon (Lithuania) and two-layer flow in the Klaipèda Strait using finite element hydrodynamic model
}

\author{
P. Zemlys ${ }^{1}$, C. Ferrarin ${ }^{2,3}$, G. Umgiesser ${ }^{2,1}$, S. Gulbinskas ${ }^{1}$, and D. Bellafiore ${ }^{2}$ \\ ${ }^{1}$ Coastal Research and Planning Institute, Klaipėda University, Manto 84, 92294 Klaipėda, Lithuania \\ ${ }^{2}$ CNR - National Research Council of Italy, ISMAR - Marine Sciences Institute in Venice, Castello 2737/f, 30122, \\ Venice, Italy \\ ${ }^{3}$ CNR - National Research Council of Italy, IAMC - Institute for the Coastal Marine Environment in Oristano, 090782, \\ Torregrande, Oristano, Italy
}

Correspondence to: P. Zemlys (petras.zemlys@ku.lt)

Received: 4 December 2012 - Published in Ocean Sci. Discuss.: 13 February 2013

Revised: 22 May 2013 - Accepted: 27 May 2013 - Published: 27 June 2013

\begin{abstract}
This work is focused on the application of a modelling system to simulate 3-D interaction between the Curonian Lagoon and the Baltic Sea coastal waters and to reflect spatiotemporal dynamics of marine waters in the Curonian Lagoon. The model system is based on the finite element programme package SHYFEM which can be used to resolve the hydrodynamic equations in lagoons, coastal seas, estuaries and lakes. The results of a one year (2009) 3-D model simulation with real weather and hydrological forcing show that the saline water intrusions from the sea through Klaipeda Strait are gradually decreasing with distance from the sea and become negligible (average annual salinity about $0.5 \%$ ) at a distance of about $20 \mathrm{~km}$ to the south of Kiaules Nugara island. Analyses of the simulation results also show this area to be highly heterogeneous according to the vertical salinity distribution. While in the deeper Klaipeda Strait (harbour waterway) differences in average salinity between near bottom and surface layers varies in the range $2-2.5 \%$, in the rest of the Curonian Lagoon it is less than $0.5 \%$. The exchange flow showed vertical structure, but was horizontally uniform with the presence of a two-directional flow that from time to time changes to either saline water one-directional flow to the Curonian Lagoon or fresh water one-directional flow to the sea. Two-directional flow duration decreases with a distance from sea entrance in Klaipeda Strait from around 180 days $\mathrm{yr}^{-1}$ close to the sea entrance to 50 days $\mathrm{yr}^{-1}$ just behind Kiaulès Nugara island. One-directional outflow dura-
\end{abstract}

tion is increasing with a distance from the sea entrance from 100 to 225 days $\mathrm{yr}^{-1}$. One-directional inflow duration occurs in the range of $70-100$ days $\mathrm{yr}^{-1}$. The analysis of the ratio of buoyancy layer thickness to water depth $\left(h_{\mathrm{b}} / H\right)$ and the Wedderburn number identified the main importance of wind action on the flow structure. Strong winds from the North and NW determine a barotropic inflow which is mostly responsible for the salt water intrusion into the Curonian Lagoon. Absence of wind or cross-strait wind regimes allows the maintenance of a two-layer flow typical of estuarine dynamics.

\section{Introduction}

Lagoons are shallow water bodies that are separated from the ocean by barrier islands or spit and connected to the ocean by one or more restricted inlets (Kjerve and Magill, 1989). Their horizontal scale ranges from several to hundreds of kilometres whereas their vertical scale is only several metres. Coastal estuarine lagoons represent a special class of estuaries where the exchange between the lagoons and the ocean is often restricted to one or several narrow inlets. Lagoons constitute about $13 \%$ of the world's coastline (Cromwell, 1973). Lagoons are an invaluable component of the nature and ecosystem of the shores and they also give comfortable possibilities for the surrounding inhabitants to develop 


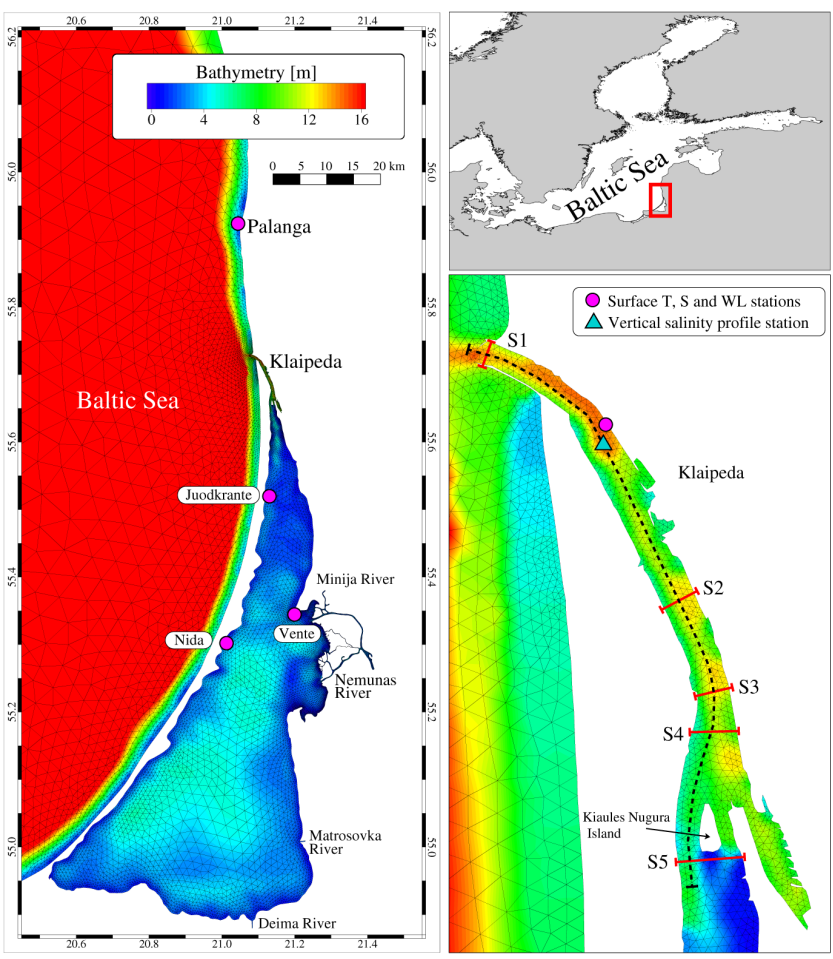

Fig. 1. Computational finite element grid of the Curonian Lagoon and coastal area of the Baltic Sea with a zoom on the Klaipeda Strait. Red continuous lines mark the location of cross-sections (S1S5) and the black dashed line marks the along-strait section. The magenta circle marks the location of the surface salinity, sea surface temperature and water level continuous monitoring stations (Klaipeda harbour station is shown on the magnified part on the right) and the cyan triangle marks the location of the vertical salinity profile station.

fishing, tourism and other activities. They are the most productive areas of the coastal environment. Previous investigations of the lagoons have mainly focused on tidal- and winddriven exchanges across the inlets (Stommel and Farmer, 1952; Wong, 1991; Geyer and Signell, 1992; Churchill et al., 1999; Luettich et al., 1999; Hench et al., 2002; Luettich et al., 2002). However, more and more attention in recent years is paid to circulation dynamics and salt balance inside the estuarine lagoons (Reyes-Hernandez and Valle-Levinson, 2010; Chen and Sanford, 2009; Jia and Li, 2012a, b; Kim and Park, 2012; Li and Li, 2012). Estuarine lagoons with complex interactions between biotic and abiotic components depend on the water exchange between the lagoon and the sea. The effective management of such a complex system cannot be limited to the results based on observations and measurements. It also requires more sophisticated tools such as mathematical models that provide scientists and decision makers with a more holistic view of the physical, chemical and biological processes.
The Curonian Lagoon, situated in the south-eastern part of the Baltic Sea, is a shallow (the average water depth is $3.8 \mathrm{~m}$ ) and large trans-boundary estuarine lagoon. The Curonian Lagoon is mainly a freshwater body connected to the southeastern part of the Baltic Sea by a narrow Klaipeda Strait (Fig. 1). It is the biggest lagoon in Europe with a surface area of about $1584 \mathrm{~km}^{2}$ and stretches in a N-S direction for nearly $100 \mathrm{~km}$. The average fresh water discharge into the lagoon is about $500 \mathrm{~m}^{3} \mathrm{~s}^{-1}$ for the Nemunas River, $124 \mathrm{~m}^{3} \mathrm{~s}^{-1}$ for the Matrosovka branch, $40 \mathrm{~m}^{3} \mathrm{~s}^{-1}$ for the Minija tributary, and $30 \mathrm{~m}^{3} \mathrm{~s}^{-1}$ for the Deima River. The Nemunas River enters the lagoon in its central area, dividing the water body into two different parts (Jurevičius, 1959). The northern part is a transitory riverine-like system transporting freshwater into the sea and receiving seawater during wind driven short term inflow events. Salinity in the northern part fluctuates from fresh water salinity to salinity of the sea $(\sim 7 \%$ ). The lacustrine fresh water southern part is characterised by a relatively closed water circulation and lower current velocities (Ferrarin et al., 2008).

Though the Curonian Lagoon is treated as shallow, the depth in different parts of the lagoon varies considerably. The artificially deepened Klaipeda Strait with a depth of 8-15 m in waterway (needed for harbour activities) is considerably deeper than the rest of the lagoon (maximum depth in the southern part of the lagoon $5.8 \mathrm{~m}$ ).

One of the problems when applying a hydrodynamic model to the Curonian Lagoon is the strong variability of needed resolution inside the lagoon. In areas like the Nemunas delta or the Klaipeda Strait, resolution of finer than $100 \mathrm{~m}$ is necessary in order to describe adequately the hydromorphological features of the area. On the other hand, inside the main water body, where bathymetric variability is low, a resolution of $500 \mathrm{~m}$ can be adopted. High resolution in these areas will lead to big numerical grids that are very demanding on CPU time. Therefore, finite-element-like models seem to be the natural candidates for the Curonian Lagoon hydrodynamic modelling.

All applications of hydrodynamic models to the Curonian Lagoon until now were focussed on investigations of horizontal water circulation patterns (Raudsepp and Kouts, 2002; Davulienė and Trinkunas, 2004; Chubarenko and Chubarenko, 1995; Ferrarin et al., 2008). Vertical heterogeneity of water circulation in Klaipeda Strait was first observed by Červinskas (1959) and was further investigated by Galkus (2007) and by Dailidienè and Davulienè (2007) using field study methods. However, there has been no model until now that has applied to the Curonian Lagoon to investigate the 3-D water circulation.

The finite element model SHYFEM has been already applied and validated in its 2-D version to the Curonian Lagoon by Ferrarin et al. (2008) comparing model results with observed water level and salinity values, confirming to be a useful tool for investigation of horizontal water circulation in the Curonian Lagoon. The numerical output of this model 
was used by Zemlys et al. (2008) to investigate the dynamics of the Curonian Lagoon ecosystem. The aim of this study was to extend previous studies, developing the 3-D SHYFEM model to reveal characteristic features of water exchange between the Curonian Lagoon and the Baltic Sea and related vertical and horizontal salinity distributions. A number of dimensionless parameters were computed in order to investigate the characteristics of the exchange flow in the Klaipeda Strait and to identify the driving processes.

\section{Materials and methods}

\subsection{The hydrodynamic model SHYFEM}

The hydrodynamic model SHYFEM used in this work is a finite element model developed at the CNR-ISMAR of Venice and successfully applied to many coastal environments (Umgiesser, 1997; Ferrarin and Umgiesser, 2005; Ferrarin et al., 2010; Bellafiore et al., 2011; De Pascalis et al., 2011). The model is freely available on the SHYFEM web page: http://www.ismar.cnr.it/shyfem.

The model resolves the 3 -D primitive equations, vertically integrated over each layer (a $z$ grid was used in this study for the vertical coordinate system), in their formulations with water level and transports:

$$
\begin{aligned}
\frac{\partial U_{i}}{\partial t}+ & \operatorname{Adv}_{i}^{x}-f V_{i}=-g h_{i} \frac{\partial \zeta}{\partial x}-\frac{g h_{i}}{\rho_{0}} \frac{\partial}{\partial x} \int_{-H_{i}}^{\zeta} \rho^{\prime} \mathrm{d} z \\
& -\frac{h_{i}}{\rho_{0}} \frac{\partial p_{a}}{\partial x}+\frac{1}{\rho_{0}}\left(\tau_{x}^{i-1}-\tau_{x}^{i}\right) \\
& +\frac{\partial}{\partial x}\left(A_{\mathrm{H}} \frac{\partial U_{i}}{\partial x}\right)+\frac{\partial}{\partial y}\left(A_{\mathrm{H}} \frac{\partial U_{i}}{\partial y}\right) \\
\frac{\partial V_{i}}{\partial t}+ & \operatorname{Adv}_{i}^{y}+f U_{i}=-g h_{i} \frac{\partial \zeta}{\partial y}-\frac{g h_{i}}{\rho_{0}} \frac{\partial}{\partial y} \int_{-H_{i}}^{\zeta} \rho^{\prime} \mathrm{d} z \\
& -\frac{h_{i}}{\rho_{0}} \frac{\partial p_{\mathrm{a}}}{\partial y}+\frac{1}{\rho_{0}}\left(\tau_{y}^{i-1}-\tau_{y}^{i}\right) \\
& +\frac{\partial}{\partial x}\left(A_{\mathrm{H}} \frac{\partial V_{i}}{\partial x}\right)+\frac{\partial}{\partial y}\left(A_{\mathrm{H}} \frac{\partial V_{i}}{\partial y}\right) \\
\frac{\partial \zeta}{\partial t}+ & \sum_{i}\left(\frac{\partial U_{i}}{\partial x}\right)+\sum_{i}\left(\frac{\partial V_{i}}{\partial y}\right)=0
\end{aligned}
$$

with $i$ indicating the vertical layer, $\left(U_{i}, V_{i}\right)$ the horizontal transport at each layer (integrated velocities), $\mathrm{Adv}_{i}^{x}$ and $\mathrm{Adv}_{i}^{y}$ the advective terms, $f$ the Coriolis parameter, $p_{\mathrm{a}}$ the atmospheric pressure, $g$ the gravitational acceleration, $\rho_{0}$ the average density of sea water, $\rho=\rho_{0}+\rho^{\prime}$ the water density calculated by the international Unesco equation of state (Unesco, 1981) using water temperature, salinity and pressure as inputs, $\tau_{x}^{i-1}, \tau_{x}^{i}, \tau_{y}^{i-1}, \tau_{y}^{i}$ the internal stress term at the top and bottom of each layer, $h_{i}$ the layer thickness, $H_{i}$ the depth at the bottom of layer $i, \zeta$ is the water level. Smagorinsky's formulation (Smagorinsky, 1963; Blumberg and Mellor, 1987) is used to parameterise the horizontal eddy viscosity $\left(A_{\mathrm{H}}\right)$. For the computation of the vertical viscosities a turbulence closure scheme was used. This scheme has been adapted to be used with staggered finite elements from the $k-\varepsilon$ module of GOTM (General Ocean Turbulence Model) described in Burchard and Petersen (1999).

The solute transport model solves the advection and diffusion equation, which, in the 3-D form, is given as:

$$
\begin{aligned}
\frac{\partial S_{i}}{\partial t}+u_{i} \frac{\partial S_{i}}{\partial x}+v_{i} \frac{\partial S_{i}}{\partial y}+w_{i} \frac{\partial S_{i}}{\partial z}=\frac{\partial}{\partial x}\left(K_{\mathrm{H}} \frac{\partial S_{i}}{\partial x}\right) \\
+\frac{\partial}{\partial y}\left(K_{\mathrm{H}} \frac{\partial S_{i}}{\partial y}\right)+\frac{\partial}{\partial z}\left(K_{\mathrm{V}} \frac{\partial S_{i}}{\partial z}\right)+E
\end{aligned}
$$

where $S_{i}$ is the concentration of any tracer (salinity or water temperature) at layer $i, u_{i}, v_{i}$ and $w_{i}$ are the velocities, $K_{\mathrm{H}}$ and $K_{\mathrm{V}}$ are respectively the horizontal and vertical turbulent diffusion coefficients and $E$ is a source/sink term. The horizontal turbulent diffusivity was calculated using the model proposed by Smagorinsky (1963), with a Smagorinsky parameter of 0.3 . Vertical diffusivities are calculated by the $k$ $\varepsilon$ turbulence closure model. Fluxes through the bottom were neglected here. The transport and diffusion equation is solved with a first-order explicit scheme based on the total variational diminishing (TVD) method (Darwish and Moukalled, 2003). In the case of salinity, the source/sink term $E$ in Eq. (4) represents the difference between evaporation and precipitation through the water surface.

In case of water temperature, the term $E$ in Eq. (4) represents the heat source through the water surface $Q / \rho c_{\mathrm{w}} H$, where $\rho$ is the water density, $c_{\mathrm{W}}$ is the specific heat of water $\left(c_{\mathrm{w}}=3991 \mathrm{~J} \mathrm{~kg}^{-1}{ }^{\circ} \mathrm{C}^{-1}\right)$ and $H$ is the depth of the fluid layer. $Q$ is the heat flux $\left(\mathrm{W} \mathrm{m}^{-2}\right)$ between the atmosphere and the sea, computed by the thermal radiative model considering short-wave radiation, long-wave radiation, heat flux generated by evaporation-condensation processes and heat flux generated by conduction-convection processes (Ferrarin and Umgiesser, 2005).

At the open boundaries the water levels are prescribed in accordance with the Dirichlet condition, while at the closed boundaries only the normal velocity is set to zero and the tangential velocity is a free parameter (Umgiesser and Bergamasco, 1995).

The model Eqs. (1-3) uses a semi-implicit algorithm for integration in time, which combines the advantages of the explicit and the implicit scheme. The terms treated implicitly are the divergence terms in the continuity equation and the Coriolis term, the pressure gradient and the bottom friction in the momentum equation; all other terms are treated explicitly. It is unconditionally stable for any time step with respect to gravity waves and allows the transport variables to be solved explicitly. Compared with a fully implicit solution 
of the shallow water equations, the dimensions of the matrix are reduced to one third.

The spatial discretisation of the unknowns has been carried out with the finite element method, partially modified from the classic formulation (Galerkin method). This modification was necessary to avoid high numerical damping and mass conservation problems, due to the combination of the semi-implicit method with the finite element scheme. With respect to the classic formulation, here the water level and the velocities (transports) are described by using form functions of different order, being the standard linear form function for the water level, but stepwise constant form function for the transports. A more detailed description of the model equations and of the discretisation method is given in Umgiesser et al. (2004) and its 3-D implementation in Bellafiore and Umgiesser (2010).

\subsection{Model implementation and simulations setup for the Curonian Lagoon}

The numerical computation has been carried out on a spatial domain that represents the Curonian Lagoon and coastal area of the Baltic Sea until the $70 \mathrm{~m}$ depth contour through a finite element grid. The grid contains 13732 nodes and 24372 triangular elements. As shown in Fig. 1, the finite element method gives the possibility to follow faithfully the morphology and the bathymetry of the system and better to represent the zones where hydrodynamic activity is more interesting and important, like the Nemunas Delta, the Klaipeda Strait, and the Matrosovka and Deima river mouths.

The water column is discretised into a maximum of 16 vertical levels with progressively increasing thickness varying from $1 \mathrm{~m}$ for the first $12 \mathrm{~m}$ to $18 \mathrm{~m}$ for the deepest layer of the outer continental shelf.

The lagoon open boundaries are the rivers and edges of the Baltic Sea area (Fig. 1). Daily river discharges were provided by the Lithuania hydro-meteorological service. Open sea boundary water temperature, salinity and water levels were obtained by spatial interpolation of 1 nautical mile spatial resolution forecasts by the operational hydrodynamic HIROMB (Funkquist, 2003) provided by the Swedish Meteorological and Hydrological Institute. The temperature and salinity initial fields were also spatially interpolated from data of model HIROMB while spatially uniform water level was used for initial condition.

Meteorological forcing fields were obtained by forecasts of the operational meteorological model HIRLAM (www.hirlam.org) provided by the Lithuania hydro-meteorological service.

The simulations have been carried out with a variable time step with a maximum value of $100 \mathrm{~s}$ for the time period between 1 January and 31 December of the year 2009.
Table 1. Model performance statistics for water level, sea surface temperature (SST) and surface salinity inside of Klaipeda Strait (Klaipeda station), inside of the Curonian Lagoon (Juodkrante, Nida, Vente stations) and in the Baltic Sea (Palanga station). See Fig. 1 for the location of the stations. Analysis results are given in terms of root-mean-square error (RMSE) and correlation coefficient between observations and model results $(R)$.

\begin{tabular}{lrrrrrr}
\hline Station name & \multicolumn{2}{c}{ Water level $(\mathrm{cm})$} & \multicolumn{2}{c}{$\mathrm{SST}\left({ }^{\circ} \mathrm{C}\right)$} & \multicolumn{2}{c}{ Surface salinity (\%o) } \\
& RMSE & $R$ & RMSE & $R$ & RMSE & $R$ \\
\hline Klaipeda & 3.2 & 0.98 & 1.2 & 0.99 & 2.3 & 0.74 \\
Juodkrante & 6.6 & 0.91 & 1.3 & 0.99 & 1.6 & 0.67 \\
Nida & 3.1 & 0.98 & 1.4 & 0.99 & - & - \\
Ventė & 4.9 & 0.95 & 1.3 & 0.99 & 0.1 & 0.60 \\
Palanga & - & - & 1.0 & 0.99 & 0.7 & 0.74 \\
\hline
\end{tabular}

\section{Results and discussion}

\subsection{Model validation}

In this study the model performance was tested using water level, sea surface temperature (SST) and surface salinity measurements acquired in three stations inside the lagoon (Juodkrante, Nida and Vente), one in the Klaipedda Strait (Klaipeda) and one in the Baltic Sea (Palanga, $25 \mathrm{~km}$ north of Klaipeda). Monitoring data were provided by Marine Research Centre of the Lithuania Environmental Agency.

Statistical analysis results are reported in Table 1 in terms of root-mean-square error (RMSE) and correlation coefficient between model results and observations $(R)$. The model reproduces the seasonal fluctuations in water level observed in the lagoon and describes well the seasonal cycle of the surface water temperature. RMSE is on average $1.2^{\circ} \mathrm{C}$ for the sea surface temperature and $4.4 \mathrm{~cm}$ for the water level. The correlation coefficient between model results and observations is on average 0.95 for the water level and 0.99 for SST.

The statistical results for the surface salinity show that RMSE is $2.3 \%$ in Klaipeda and varies between 1.6 and $0.1 \%$ inside the lagoon. Correlation between observed and modelled surface salinity is 0.74 in Klaipeda and decreases going southward into the lagoon due to the episodic behaviour of the salt water intrusion (see next section). The ability of the model in reproducing saline water intrusions is shown in Fig. 2 as a time-series of observed and modelled surface salinity in the Klaipeda harbour. The model performance is not the same through the year. In winter and early spring the model tends to produce higher salinity peaks than observed while in the other periods of the year the model performance is considerably better. Worse model performance in winter time may be related to the ice cover on the Curonian Lagoon that is still not simulated by the model.

Vertical salinity distribution in Klaipeda Strait was tested using Klaipeda harbour monitoring data provided by Coastal Research and Planning Institute of the Klaipeda University. Figure 3 shows the correspondence between measured (only 


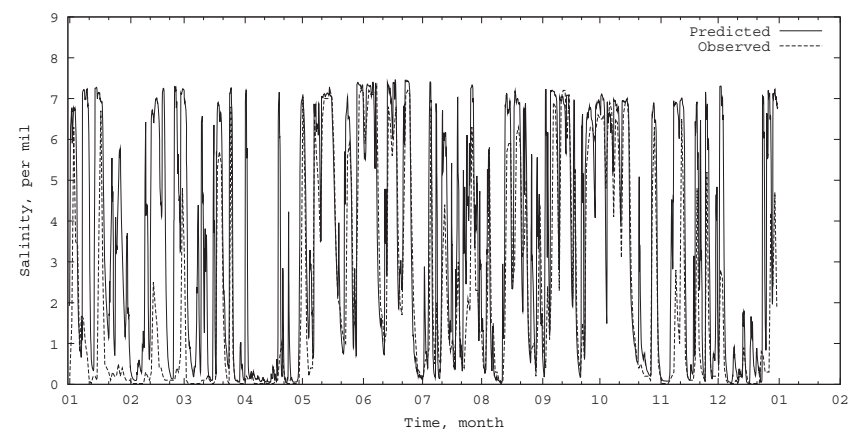

Fig. 2. Time-series of observed and modelled surface salinity in the Klaipeda harbour.

surface and near-bottom salinity was measured) and modelled vertical salinity profiles at different times in 2009 with different salinity vertical gradients. Both for the fully mixed case (Fig. 3d) and at different salinity gradients (Fig. 3a, $\mathrm{b}, \mathrm{c})$ the model performance can be considered satisfactory. The figures are representative mostly of summer situation. As mentioned above, during winter the data reproduction is less satisfactory, probably due to the ice coverage, not modelled.

\subsection{Dynamics of sea water intrusion and of water circulation}

In this section, we investigate the mean salinity and the mean circulation in the northern part of the Curonian Lagoon and in the Klaipeda Strait. To characterise the horizontal salinity distribution three variables were derived from simulation results: annual average of vertically-averaged salinity, annual maximum of vertically-averaged salinity and number of days when vertically-averaged salinity is greater than $0.5 \%$ o further called saline water exposition time. The maps with horizontal distribution of these variables for the Curonian Lagoon and Klaipèda Strait are presented on Fig. 4a, b, c. As one can see from Fig. 4a the highest annual average salinities of 3-5.5\% are observed in the Klaipeda Strait. It gradually decreases with distance from the sea entrance going to the south and reaches fresh water salinity level $(0.5 \%)$ at a distance of approximately $35 \mathrm{~km}$ from the sea entrance. The map of annual maximum salinities (Fig. 4b) shows that during single events saline water intrusions on the eastern coast can reach the central part of the Curonian Lagoon while on the western coast, where the influence of the Nemunas fresh water discharge is weaker, it can go even further and reach the southern part of the Curonian Lagoon. Saline water exposition time has similar patterns as the horizontal distribution of annual average salinity. The highest saline water exposition time (250-364 days) is observed in the Klaipeda Strait (Fig. 4c). It gradually decreases with distance from the Sea entrance going to the South. The value of 25 days is reached at a distance of $40 \mathrm{~km}$ from the sea entrance.
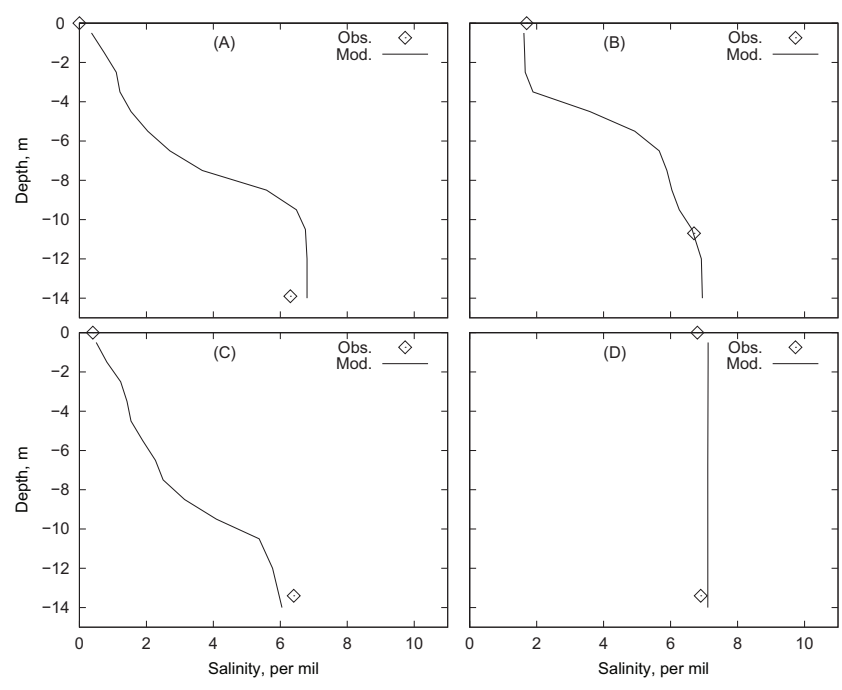

Fig. 3. Measured and modelled vertical salinity profile in Klaipeda Strait at different time: (A) 5 February 2009, (B) 10 June 2009, (C) 6 August 2009, (D) 8 September 2009.

For the investigation of horizontal distribution for salinity vertical gradient strength the difference between bottom layer salinity and surface layer salinity is shown in Fig. 4d. The highest differences between surface and bottom salinity $(2.5-3 \%$ o) are observed in Klaipeda Strait (Fig. 4d). To the south of Kiaules Nugara Island the differences in most cases are less than $0.5 \%$. This result indicates that Klaipeda Strait is the most interesting area from the point-of-view of vertical stratification and possibility to observe two-layer water flow.

Salinity in the northern part of the Curonian Lagoon not only shows large spatial variation, but also undergoes large temporal variation because of variation in the meteo-marine forcing. In order to investigate the temporal variation of the intrusion of salty water into the lagoon, the salt flux through the southern end of the Klaipeda Strait was computed using water flux and salinity values computed by the model in each node and in each layer of cross-section S5 (see Fig. 1). As shown in Fig. 5c, the water level in the northern part of the lagoon ( $\zeta_{\text {lagoon }}$, blue continuous line) follows the synoptic water level variation in the Baltic Sea $\left(\zeta_{\text {sea }}\right.$, red dotted line; both levels are referred to the same datum). Because of the fresh water discharge from Nemunas, Matrosovka branch, Minija and Deima rivers (Fig. 5a), the water level inside the Curonian Lagoon is generally higher than in the shelf sea in front of the Klaipeda Strait. Therefore, there is a net outflow of water from the lagoon to the sea (Ferrarin et al., 2008).

Short-term water level differences between the lagoon and the open sea are mainly dependent on the wind forcing (Fig. 5b). Water level in the shelf sea is usually higher than in the northern part of the lagoon during southward winds (red band). This is due to the water level setup in the Baltic Sea and the wind induced modulation of water level inside the shallow Curonian Lagoon, with higher values in the southern 

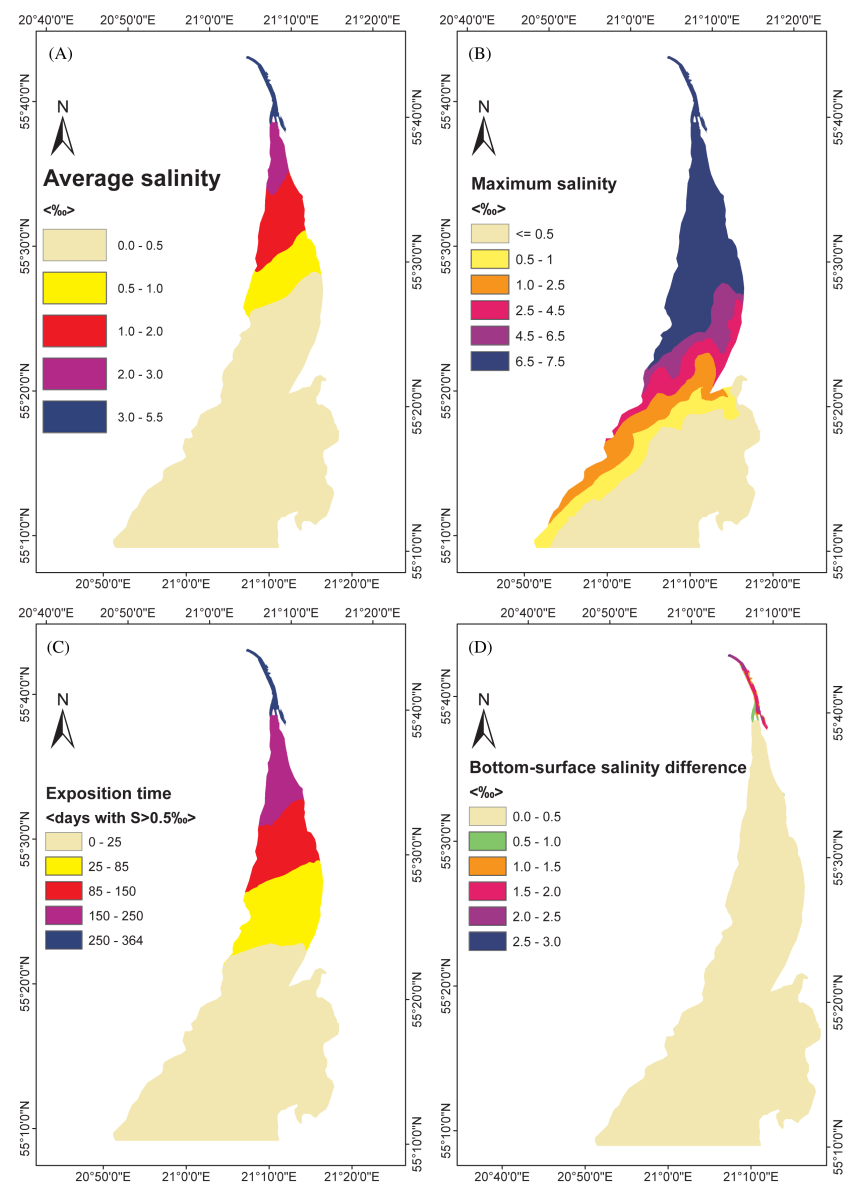

Fig. 4. Spatial distribution in the northern part of the Curonian Lagoon of (A) annual average of vertically-averaged salinity, (B) yearly maximum of vertically-averaged salinity, (C) number of days per year when vertically-averaged salinity stays greater than $0.5 \%$, (D) difference between annual average of surface and near bottom layer salinity.

part of the lagoon and lower ones in the north. The northsouth water level difference inside the lagoon can be up to $80 \mathrm{~cm}$ during intense storm events (not shown). However, due to the very shallow depth of the basin, when the wind stops blowing, these oscillations are rapidly damped out by bottom friction. Water fluxes through the strait are mainly controlled by the sea-lagoon water level difference with a correlation coefficient $R$ of 0.92 .

Figure $5 \mathrm{~d}$ shows the temporal variation of the salt flux through cross-section S5 and the depth averaged salinity at the southern end of the Klaipeda Strait (black line). Model results indicate that, generally, southward winds lead to an intrusion of salty water (having average salinity of $7 \%$ ) into the Curonian Lagoon, while outflow is associated with northward winds or low intensity winds (Fig. 5d). There is a statistically significant correlation $(R=0.71)$ between the water level difference along the Klaipeda Strait and the salt flux through the strait. Therefore, the wind driven barotropic pres-
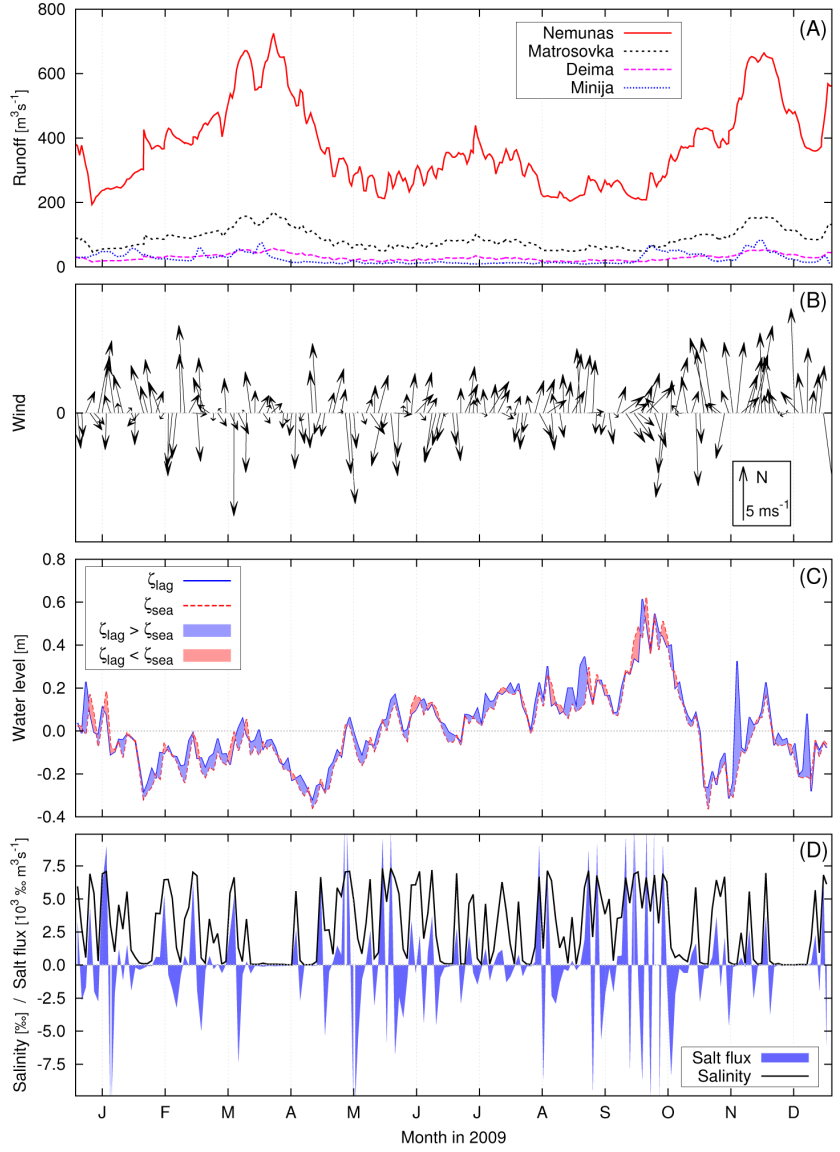

Fig. 5. Time series of (A) fresh water discharge into the lagoon, (B) wind speed vector azimuth in the northern part of the lagoon, $(\mathbf{C})$ modelled water level in the open shelf in front of the lagoon (red dotted line) and in the northern part of the lagoon (blue continuous line), (D) modelled salt flux through cross-section S5 (blue band; positive value indicates flow toward lagoon and negative value indicates flux seawards) and depth averaged salinity in the northern part of the lagoon (black line).

sure gradient due to water level slope along the Klaipeda Strait is the main driver of the barotropic salt exchange between the Baltic Sea and the Curonian Lagoon. During intense southward wind events, and when river discharge is low river discharge, intrusion of salt water can reach the central part of the lagoon (Fig. 4b).

\subsection{The water flow dynamics in Klaipèda Strait}

The maps of yearly averages for surface and bottom layer currents in Klaipeda Strait are presented in Fig. 6. The dominant current for the surface layer (Fig. 6a) is seaward with maximum current speed of $20 \mathrm{~cm} \mathrm{~s}^{-1}$. For the bottom (Fig. 6b) layer in most areas of the strait that correspond to areas with highest depth (see Fig. 1) we have currents of opposite, i.e., landward direction. That means that water flow from the sea to the lagoon is dominant in the bottom layer. 


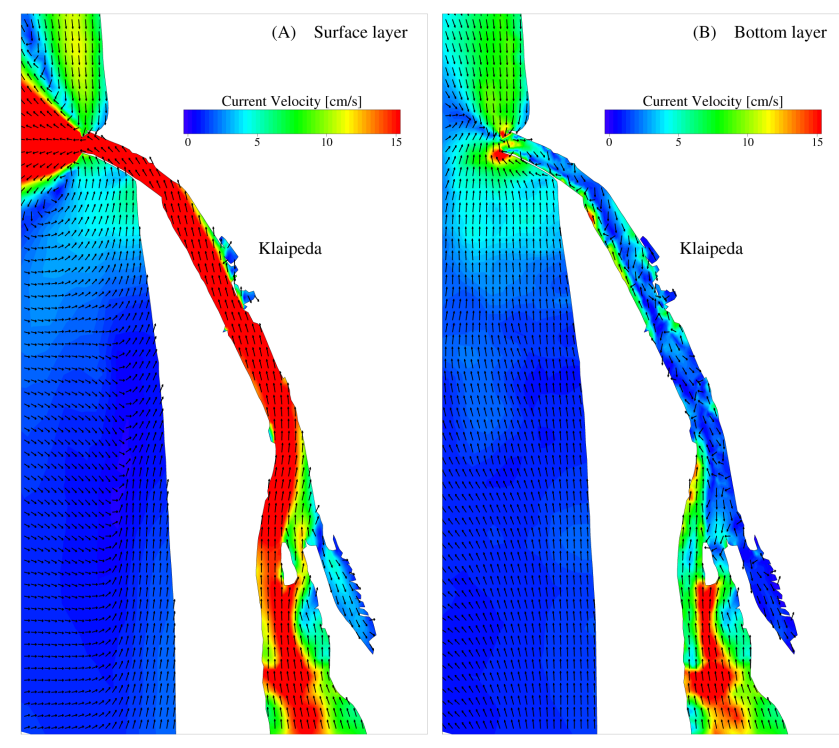

Fig. 6. Maps of yearly averaged modelled surface (A) and bottom (B) currents in the Klaipeda Strait.

This clearly indicates the presence of two-directional water flow in the strait. To investigate the water flow properties in a more detailed way, the water discharge and flow direction (inflow or outflow from Klaipeda Strait) were calculated for each layer in five cross-sections shown in Fig. 1. Calculation of total discharge for each direction in the cross-section lets define periods and intensity of different types of flow: (1) one-directional fresh water flow seaward, (2) one directional saline water flow into the lagoon, (3) two-directional (twolayer) flow in with a buoyant outflow in the surface layers and saline water intrusion in the bottom.

An example of each of the three flow regimes is given in Fig. 7. Figure 7a shows that all three types of flows are detected. In order to identify the vertical salinity patterns in each flow regime, Fig. 7b-d shows also along-strait sections for the three example cases. Figure $7 b$ shows an event driven by water coming from the lagoon, mainly freshwater, well mixed through the water column. In this case the freshwater encounters a vertical front of more saline water just outside the strait. In Fig. 7c a characteristic inflow regime is shown. There is no stratification and saline sea waters (salinity $>6 \%$ o) reach the innermost part of the strait. The third flow regime type, shown in Fig. 7d, requires a more comprehensive description, presenting a typical estuarine two-layer flow; stratification is present almost in the whole length of the strait, except for the innermost part: the presence of a sill divides the flow pattern; in an inner-estuary well-mixed freshwater outflow, while, seaward with respect to the sill (approximately near Sect. S5), a weak saline inflow is detected below $5 \mathrm{~m}$ depth. In the area between Sects. S4 and S3, a second orographic obstacle is present that obstructs further intrusion of more energetic saltier water (velocities around $0.3 \mathrm{~m} \mathrm{~s}^{-1}$ comparable with surface outflow speed) coming from the sea. Therefore, a fully developed two-layer flow regime characterises this area. The role of sills in controlling the bottom water exchange in straits is a topic of interest in the literature (Valle-Levinson et al., 2001; Caceres et al., 2004). Similar salinity and velocity patterns are seen in the outermost strait of Kotor Bay (Montenegro), where the presence of a sill is responsible for the stabilisation of a thermohaline front with the creation of recirculation cells (Bellafiore et al., 2011).

For a comparison of different types of flow it is important to decide what flow intensity is treated as negligible, because numerically we can have many small non-zero flow values that should not be treated as significant if they are small in comparison with typical flows in the considered area. The threshold value below which the flow should be treated as negligible was chosen to be equal to $2 \%\left(\sim 10 \mathrm{~m}^{3} \mathrm{~s}^{-1}\right)$ of the difference between annual average flow to the sea and annual average flow from the sea $\left(\sim 500 \mathrm{~m}^{3} \mathrm{~s}^{-1}\right)$. Total duration (days $\mathrm{yr}^{-1}$ ) was calculated for each type of flow. The results are presented in Fig. 8. As one can see, duration of two-directional flow decreases with a distance from the sea entrance from around 180 days $\mathrm{yr}^{-1}$ for the first cross section to 50 days $\mathrm{yr}^{-1}$ for 5 th cross section. One-directional outflow duration is increasing with a distance from the sea entrance from 100 to 225 days $\mathrm{yr}^{-1}$. One-directional inflow duration is almost the same for all sections fluctuating in the range $70-100$ days $\mathrm{yr}^{-1}$. For the first two cross sections, the longest duration is for two-directional flow, while for other cross sections one-directional outflow is dominant.

In order to compare the volume flux magnitudes of opposite two-directional flow, the following measure of average relative magnitude was introduced:

$D=\frac{1}{n} \sum_{i} \frac{\min \left(\left|f_{i 1}\right|,\left|f_{i 2}\right|\right)}{\max \left(\left|f_{i 1}\right|,\left|f_{i 2}\right|\right)} \cdot 100$

where $D$ is relative magnitude measure, $f_{i 1}, f_{i 2}$ are opposite direction flow magnitudes, $\mathrm{m}^{3} \mathrm{~s}^{-1}$ at any time moment, $i$ is time step number, $n$ is number of time steps with twodirectional flow. The maximal value $D=100 \%$ means that flow magnitudes are equal and no one of the two-directional flows is dominant, $D<100 \%$ means that one flow dominates and that the smaller flow is $D$ percent of the maximal flow. The average relative magnitude for different cross sections is presented in Fig. 9. We can see that flows are never equal: one of the flows is always dominant. However smaller-intensity flows still make up on average $17-25 \%$ of the discharge in the larger-intensity flow what after calculation gives $14-20 \%$ in total flow intensity through the strait. It means that flows of both directions are significant in the sense of flow intensity through the strait.

The relative contribution of water temperature to stratification in the Klaipeda Strait was estimated as the ratio between the thermal induced vertical density gradient (imposing the vertically averaged salinity) and the vertical density gradient 

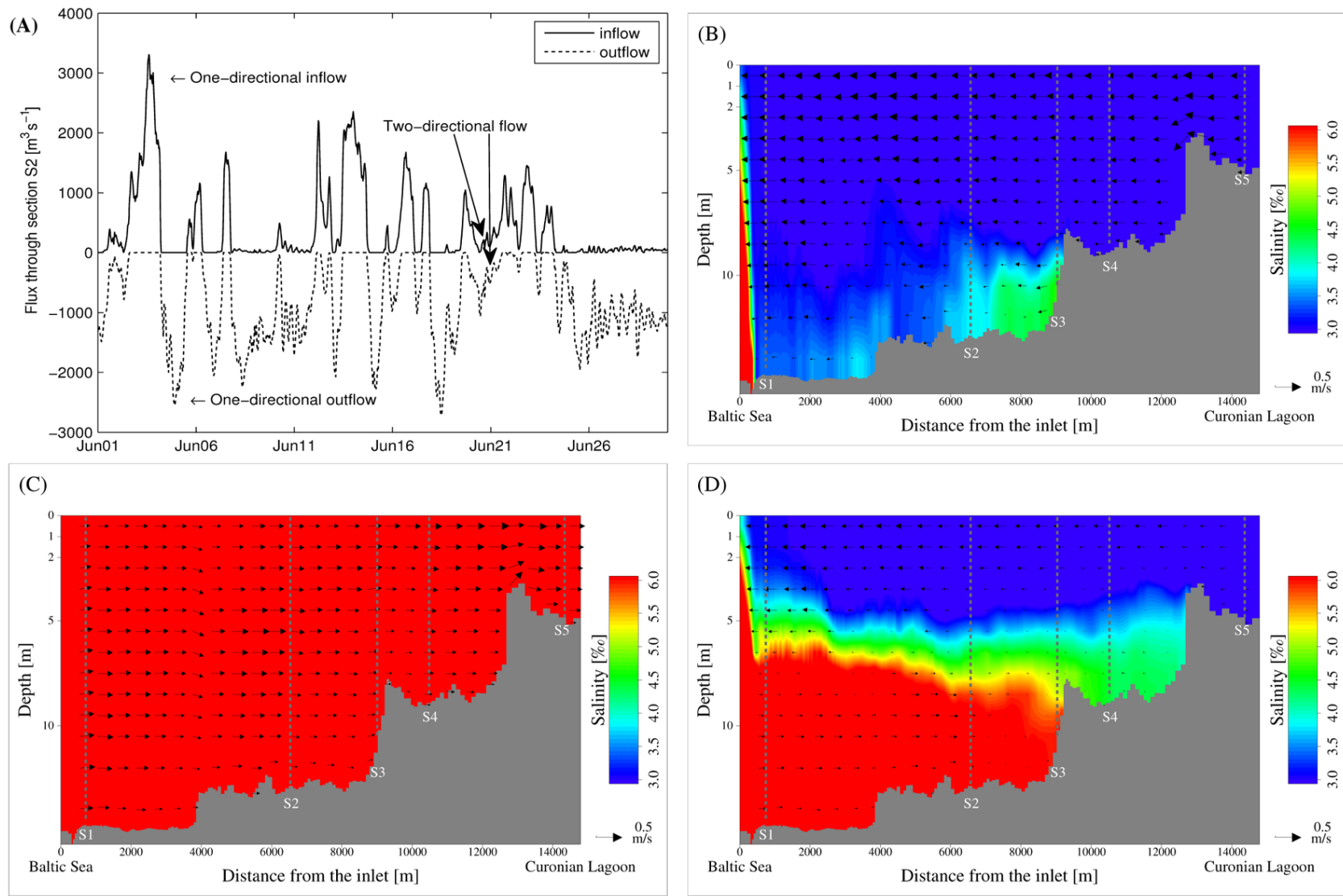

(D)

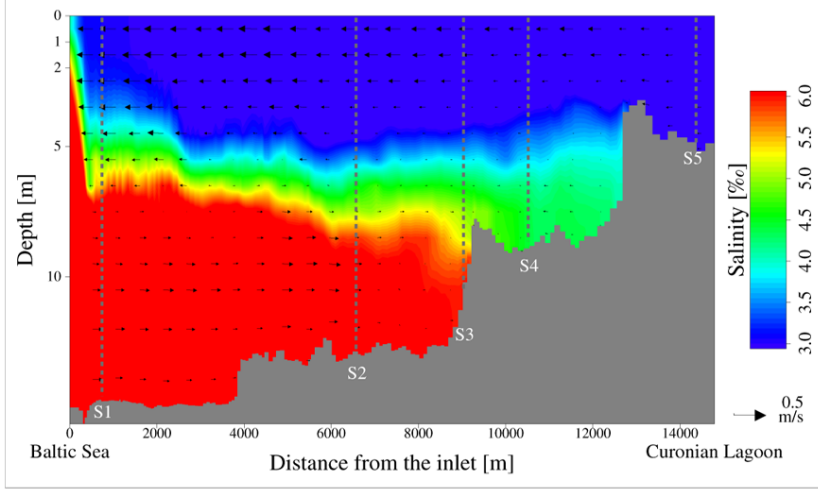

Fig. 7. Water flow through cross-section S2 in June 2009 ((A), continuous line for inflow and dotted line for outflow) and different flow regimes in the Klaipeda Strait: (B) unidirectional outflow, (C) unidirectional inflow, (D) two-layer flow. Grey dotted lines in panels $(\mathbf{B}),(\mathbf{C})$, (D) indicate the approximate location of cross-sections S1-S5.

determined by both water temperature and salinity (deCastro et al., 2006). The results of this analysis showed that the vertical salinity gradient controls water stratification in the strait. The water temperature contribution to vertical stratification is on average less than $5 \%$, with peak values of $20 \%$ during summer.

Straits and estuarine systems can be characterised by several kinds of flow regimes and a crucial point is to determine what are the driving forcings. The exchange flow in a strait system can be vertically and laterally (across the strait) sheared and the relative degree of shearing can be estimated by computing the Kelvin number (Ke), which compares the estuary width $(B)$ to the internal Rossby radius (Ri), and the Ekman number (Ek), which compares frictional to Coriolis effects (Valle-Levinson, 2008). The Kelvin number for the considered narrow strait (about $500 \mathrm{~m}$ wide and $12 \mathrm{~m}$ depth) is always lower then 1 (the average value is 0.25 ). Therefore, Earth's rotation effects on density-induced or windinduced water exchange are not appreciable and the buoyant outflow flows across the entire width of the strait. The estimated Ekman number has an average value of 0.03. Such low value of the Ekman number indicates that the Klaipeda
Strait is characterised by moderate frictional conditions. According to the classification of estuaries proposed by ValleLevinson (2008), these values of Ke and Ek suggest that the Klaipeda Strait displays preferentially vertically sheared and horizontally uniform flow.

The surface wind stress can be a competing driver explaining the flux dynamics through the water column. For example, Valle-Levinson et al. (2004) showed, from measurements, how the balance between wind stress and barotropic pressure gradients justifies the vertical integrated dynamics for a specific strait in the Chilean Sea. In order to investigate the wind effects on stratification of waters in the Klaipeda Strait and type of flow regime, two governing dimensionless parameters are identified: the Wedderburn number $(W)$, defined as the ratio of wind stress to axial baroclinic pressure gradient force, and the ratio of the buoyancy layer depth to water depth $\left(h_{\mathrm{b}} / H\right)$ (Chen and Sanford, 2009). The Wedderburn number (Monismith, 1986) describes the relative importance between the wind-driven circulation and the baroclinic pressure gradient along the strait:

$W=\frac{\tau_{w x} L}{\Delta \rho g H^{2}}$ 


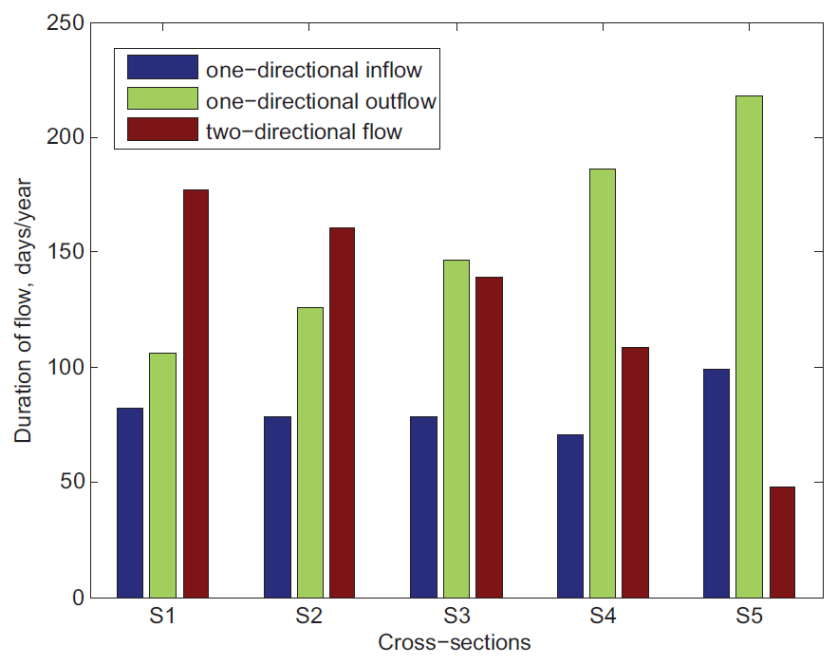

Fig. 8. Distribution of duration per year 2009 for different types of flows in the sections displayed in Fig. 1.

where $\tau_{w x}$ is the along-strait wind stress (positive up-strait, e.g., towards the lagoon), $L$ is the length of the strait $(14 \mathrm{~km})$, $\Delta \rho$ is the density change over $L, g$ is the gravitational acceleration, and $H$ is the averaged depth of the strait $(11 \mathrm{~m})$. The wind driven circulation dominates when $|W|>1$, whereas the gravitational force dominates when $|W| \sim 0$. The buoyancy layer depth $\left(h_{\mathrm{b}}\right)$ is here estimated by the maximum buoyancy frequency (as a function of depth) in the central part of the strait, in correspondence with section S2. The ratio of the buoyancy layer depth to water depth $\left(h_{\mathrm{b}} / H\right)$ ranges between 0 and 1 ; it is close to 0 when saline water tends to homogenise the water column, whereas it is close to 1 when fresh water occupies most of the water column. Therefore, if $h_{\mathrm{b}} / H$ is close to the extremes of the range $[0,1]$ marine or riverine mixed flow regimes are identified while, for intermediate values, the two-layer flow regime occurs.

Time-series of the $W$ and $h_{\mathrm{b}}$ were computed from hourly modelled salinity and temperature values and wind records obtained by the HIRLAM meteorological model for the Klaipeda Strait. The whole datasets of $W$ and $h_{\mathrm{b}} / H$ were divided in sub-samples depending on wind regimes (dividing wind speed events greater than $3 \mathrm{~m} \mathrm{~s}^{-1}$ in the eight principal sectors, $45^{\circ}$ wide each, and considering the no-wind situation when wind speed is lower than $3 \mathrm{~m} \mathrm{~s}^{-1}$ ). Using $W$ and $h_{\mathrm{b}} / H$ as two axes, we may construct a flow-regime diagram to classify wind controls on stratification (Fig. 10). Each symbol in the diagram identifies the mean values of $W$ and $h_{\mathrm{b}} / H$ for each sub-sample. We here adopted the meteorological convention, therefore directions indicate wind provenance.

Looking at the wind rose shown in the upper right corner of Fig. 10, the main wind regimes in the area are blowing from SE and WW-SW, reaching for the latter regime wind speeds exceeding $12 \mathrm{~m} \mathrm{~s}^{-1}$ in $1 \%$ of the cases. The main axis of the strait is in the direction NW-SE, therefore

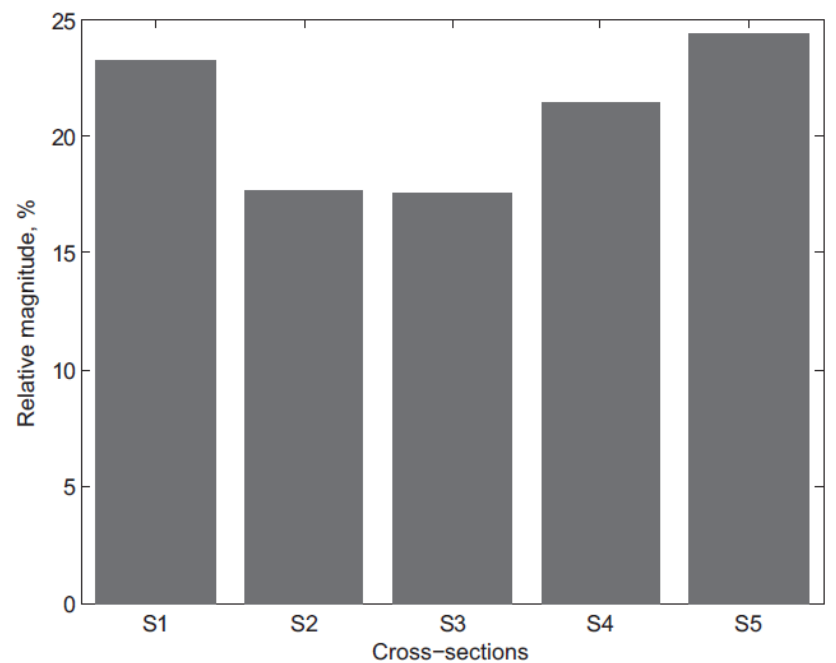

Fig. 9. Average relative magnitude of flows in two-directional flow regime.

the wind regimes that fall in line with the axis are more effective on flow regimes. In fact, up-strait winds (NN and $\mathrm{NW}$ ), even if they are not the majority of events, strongly reduce stratification (mean $h_{\mathrm{b}} / H<0.2, W \gg 1$ ) and enhance a wind-driven circulation which is responsible for the onedirectional well mixed marine inflow towards the lagoon. Even if this barotropic inflow regime is only active during about one quarter of the year (Fig. 8), according to our calculations it is responsible for more than $90 \%$ of the total salt mass inflow to the lagoon. This process has been identified in several estuaries (Chen and Sanford, 2009; Reyes-Hernández and Valle-Levinson, 2010; Jia and Li, 2012a) and can be seen in Fig. 7c during northward wind events. The mean values of $W$ are 7.3 and 8.8 for $\mathrm{NN}$ and $\mathrm{NW}$ wind regimes, respectively, clarifying, in this case, the main importance of wind action in driving the circulation, compared with buoyancy forces.

Analysing cross-strait winds, specifically the subsample of WW wind events, which is one of the two main wind regimes, the graph shown in Fig. 10 identifies a clear twolayer flow regime $\left(h_{\mathrm{b}} / H\right.$ is around 0.35$)$ where wind action is less defined than in the along-strait wind regimes from $\mathrm{NN}$ and NW but still present ( $W \sim 3.5$, substantially greater than 1). What can be deduced is a relative influence of wind, also considering the frequent occurrence of this wind regime, even if the mixing action is attenuated by the cross-strait direction, allowing a two-layer flow often.

Interestingly, both the along-strait components of EE and SW wind events, that are less present and less intense in speed than other wind regime, concur in similar flow regimes even if their directions are opposite. They act in creating a two-layer flow $\left(h_{\mathrm{b}} / H\right.$ is 0.5 and 0.6 , respectively) with a balance between down-strait wind stress and gravitational forces $(W \sim-1)$. The along-strait component of NE wind regime, 


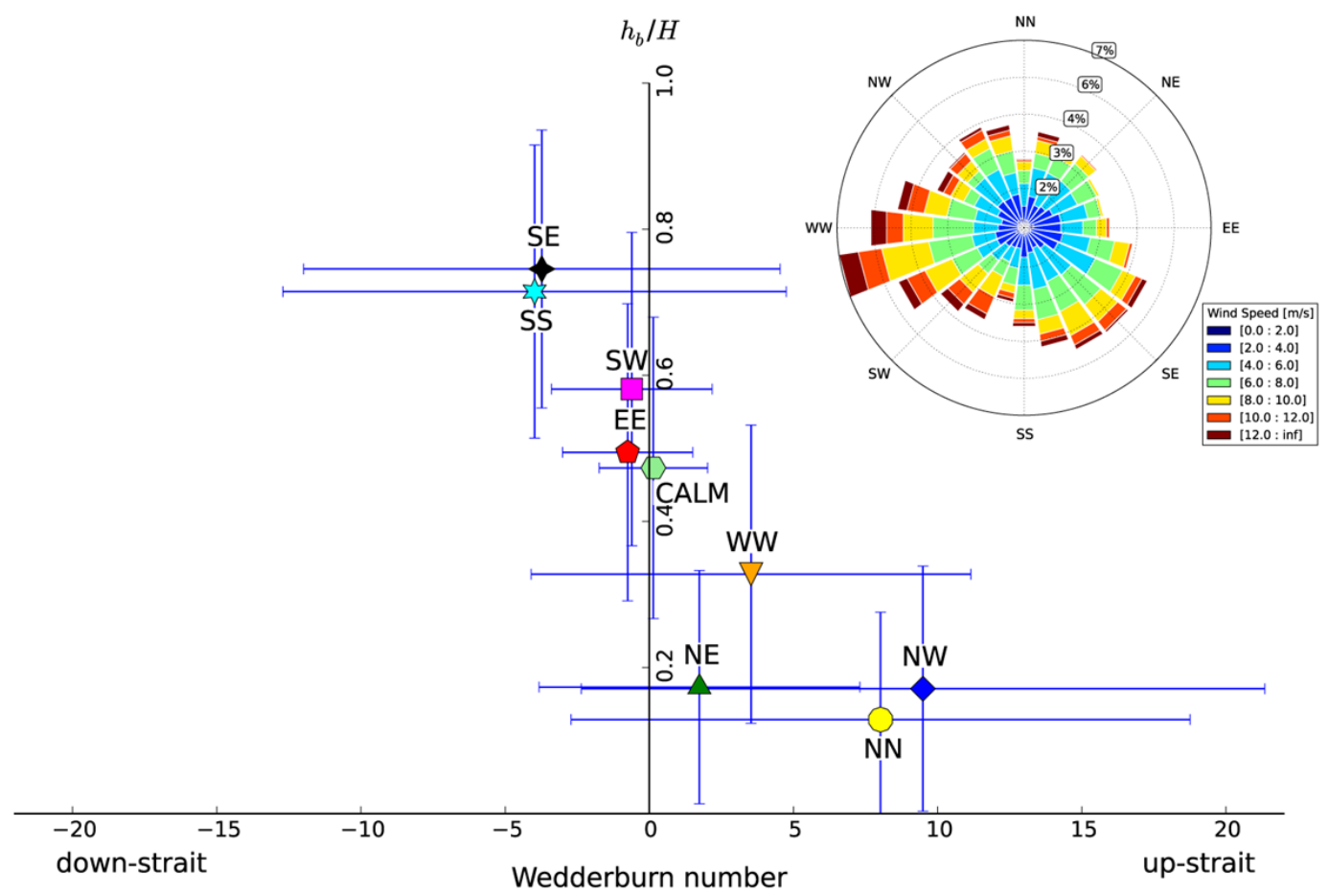

Fig. 10. Flow-regime diagram to classify the effect of the wind on stratification in the Klaipeda Strait. The y-axis is the ratio of buoyancy layer depth $\left(h_{\mathrm{b}}\right)$ to total water depth $(H)$; the x-axis is the Wedderburn number $(W)$. Positive is up-strait and the blue error-bars indicate the standard deviation of $W$. Symbols identify the mean values of each sub-sample based on the wind direction (from NN, NE, EE, SE, SS, SW, WW and NW) and the no-wind situation (CALM; sub-sample of cases with wind intensity lower than $3 \mathrm{~m} \mathrm{~s}^{-1}$ ). In the upper right panel the wind rose obtained from HIRLAM model results for the Klaipeda Strait is shown.

that is not as frequent as the previous two, is slightly more effective in producing an up-strait stress $(W \sim 2)$ thinning the surface out-flowing buoyant layer if compared with the majority of saltier water column $\left(h_{\mathrm{b}} / H<0.2\right)$.

When strong down-strait wind is blowing over the system (SE and SS), the water column is de-stratified (mean $h_{\mathrm{b}} / H>$ 0.7 ) leading to a unidirectional seaward flow of lower salinity waters. The mean Wedderburn number is around -3.5 for these wind regimes indicating that the wind-driven circulation is stronger than the gravitational circulation. The predominance of wind stress can be connected both with the fact that the along-strait component of these two regimes is significant and that they occur frequently of them (SE wind regime is one of the main ones in the region).

During calm situations and moderate down-strait winds the gravitational circulation dominates over the wind driven circulation $(\mathrm{W} \sim 0)$, the water column becomes more stratified and the Klaipeda Strait is characterised by a two-layer flow regime $\left(h_{\mathrm{b}} / H \sim 0.5\right)$, typical of partially mixed estuaries (Dyer, 1997). The fresh water lies over a layer of saline water that extends into the strait and vertical mixing is inhibited by the stratification. The degree of stratification and the relative amount of vertical mixing depend mainly upon the fresh water discharge into the lagoon.
Trying to summarise the main outcomes that can be deduced from Fig. 10, three main flow regimes can be identified: the first is a well-mixed inflow of marine water enhanced by northerly winds (NN, NW) and also present but less defined for NE winds; the second regime is a well-mixed outflow of fresher waters when winds are blowing from SS and SE; the third one is a two-layer flow, with surface fresh waters out-flowing and bottom saltier waters inflowing the strait, when winds are calm or the wind events are mainly acting in the across-strait direction.

\section{Conclusions}

In this paper, a 3-D finite element model of the Curonian Lagoon has been presented. A one year simulation with real meteorological and hydrological forcing was carried out in order to investigate horizontal and vertical salinity distribution of the Curonian Lagoon and flow properties during water exchange between lagoon and the Baltic Sea. 3-D model simulation results let us draw the following conclusions:

- Analysis of vertically-averaged salinity horizontal distribution shows that saline water intrusions from the Baltic Sea are important for the northern part of the Curonian Lagoon raising average salinity considerably 
with a decrease to the south. The highest salinity (annual average of vertically-averaged salinity $2.5-3 \%$ ) is observed in the Klaipeda Strait that connects the Curonian Lagoon with the Baltic Sea. It gradually decreases with distance from the sea and becomes negligible (annual average of vertically-averaged salinity about $0.5 \%$ ) in a distance of about $20 \mathrm{~km}$ to the south of the island $\mathrm{Ki}$ aulès Nugara. The Klaipeda Strait is exposed to saline water (salinity higher than $0.5 \%$ ) for 250-364 days per year. Saline water exposition time is decreasing going to the south. The isoline with saline water exposition of 25 days is located at a distance of $40 \mathrm{~km}$ from the sea entrance.

- Vertical salinity gradient is strong for the Klaipeda Strait. The salinity difference between annual average salinity of the bottom and surface layers reaches 2.5$3 \%$ while to the south of Kiaulès Nugara it is less than $0.1 \%$.

- Stronger salinity gradients in the Klaipeda Strait create conditions for more complex nature of water flow through the strait. The exchange flow showed vertical structure but was horizontally uniform (Kelvin number equal to 0.25 and Ekman number equal to 0.03) and three types of flow regime are identified: (1) onedirectional inflow, (2) one-directional outflow, (3) twodirectional flow.

- The duration of each flow regime type and relative magnitude of opposite-direction flows for two-directional flow was evaluated using model results. Two-directional flow duration decreases with distance from the sea entrance in Klaipeda Strait from around 180 days $\mathrm{yr}^{-1}$ for the first cross section to 50 days $\mathrm{yr}^{-1}$ for the 5 th cross section. One-directional outflow duration is increasing with a distance from the sea entrance from 100 to 225 days $\mathrm{yr}^{-1}$. One-directional outflow duration is almost the same for all sections fluctuating in the range 70100 days $\mathrm{yr}^{-1}$. For the first two cross sections twodirectional flow has the longest duration, while for other cross sections one-directional outflow is dominating.

- One of the opposite direction flows in two-layers flow is always dominant by intensity. However, the smallermagnitude flows still make up in average $17-25 \%$ of the discharge with respect to the larger-magnitude flow or $14-20 \%$ in total flow intensity trough the strait. This means that flows of both opposite directions are significant in the sense of flow intensity trough the strait.

- Salt water intrusion into the Curonian Lagoon is mainly determined by barotropic inflows driven by the sealagoon water level difference.

- The analysis of the ratio of the buoyancy layer thickness to water depth $\left(h_{\mathrm{b}} / H\right)$ and the Wedderburn number allowed identification of the importance of wind action in the along-strait direction to enhance both well mixed inflows and outflows. Absence of wind or cross-strait wind regimes keeps a two-layer flow typical of estuarine dynamics.

The hydrodynamic model will be next coupled with an icecover model to improve the description of the estuarine dynamics during winter conditions. The adopted methodology is a powerful tool for providing essential information for ecological research, for development of ecological models, for environmental decision-making and could help to predict the impact on the Curonian Lagoon of harbour area dredging and climate change.

Acknowledgements. The authors thank the HIROMB cooperation and especially Swedish Meteorological and Hydrological Institute for provided predictions of operational hydrodynamic model HIROMB that were used in this study as boundary condition data, Lithuanian Hydrometeorological service for data required for meteorological and hydrological forcing, Marine Research department of Environmental Protection Agency of Lithuania for permanent monitoring data. This study was funded by Norwegian Financial Mechanism and Republic of Lithuania (project No. LT0047), and by European Social Fund under the Global Grant measure (CISOCUR project VP1-3.1-ŠMM-07-K-02-086) and by RITMARE Flagship Project, funded by MIUR under the NRP 2011-2013, approved by the CIPE Resolution 2/2011 of 23 March 2011.

Edited by: J. M. Huthnance

\section{References}

Bellafiore, D. and Umgiesser, G.: Hydrodynamic coastal processes in the North Adriatic investigated with a 3-D finite element model, Ocean Dyn., 60, 255-276, 2010.

Bellafiore, D., Guarnieri, A., Grilli, F., Penna, P., Bortoluzzi, G., Giglio, F., and Pinardi N.: Study of the hydrodynamical processes in the Boka Kotorska Bay with a finite element model, Dyn. Atmos. Oc., 52, 298-321, 2011.

Blumberg, A. and Mellor, G. L.: A description of a threedimensional coastal ocean circulation model, in: ThreeDimensional Coastal Ocean Models, edited by: Heaps, N. S. , American Geophysical Union, Washington, DC, 1-16, 1987.

Burchard, H. and Petersen, O.: Models of turbulence in the marine environment - a comparative study of two equation turbulence models, J. Marine Syst., 21, 29-53, 1999.

Churchill, J. H., Hench, J. L., Luettich, R. A., Blanton, J. O., and Werner, F. E.: Flood tide circulation near Beaufort Inlet, North Carolina: Implications for larval recruitment, Estuar. Coast., 22, 1057-1070, 1999.

Cromwell, J.: Barrier coast distribution: A world-wide survey, in: Barrier Islands, edited by: Schwartz, M. L., Dowden Hutchinson Ross, Stroudsburg, Pa, 407-408, 1973.

Cáceres, M. and Valle-Levinson, A.: Transverse variability of flow on both sides of a sill/contraction combination in a fjord-like inlet of southern Chile, Estuar. Coast. Shelf Sci., 60, 325-338, 2004. 
Červinskas, E.: The Main Features of the Hydrological Regime. In: Curonian Lagoon Results of a Complex Investigation, Vilnius, 47-67, 1959 (in Russian).

Chen, S. and Sanford, L.: Axial wind effects on stratification and longitudinal salt transport in an idealized, partially mixed estuary, J. Phys. Oceanogr., 39, 1905-1920, 2009.

Chubarenko, B. V. and Chubarenko, I. P.: Modelling of currents in the Curonian Lagoon during storm wind influence, Meteorol. Hydrol., 5, 54-60 , 1995 (in Russian).

Darwish, M. S. and Moukalled F.: TVD schemes for unstructured grids, Int. J. Heat Mass Trans., 46, 599-611, 2003.

Dailidiene, I. and Davuliene, L.: Long-term mean salinity in the Curonian Lagoon in 1993-2005, Acta Zoologica Lituanica, 17, 172-181, 2007.

Davulienè, L. and Trinkūnas, G.: Circulation dynamics in the Curonian Lagoon waters Lithuanian, Lith. J. Phys., 44, 67-73, 2004.

deCastro, M., Gómez-Gesteira, M., Álvarez, I., and Prego, R.: Seasonal evolution of the transverse thermohaline asymmetry in the Ria de Pontevedra (northwestern Spain), Estuarine, Coast. Shelf Sci., 70, 673-681, 2006.

De Pascalis, F., Pérez-Ruzafa, A., Gilabert, J., Marcos, C., and Umgiesser, G.: Climate change response of the Mar Menor coastal lagoon (Spain) using a hydrodynamic finite element model, Estuarine, Coast. Shelf Sci., 114, 118-129, , 2011.

Dyer, K. R.: Estuaries, A Physical Introduction, 2nd Edn., John Wiley \& Sons, Chichester, 195 pp., 1997.

Ferrarin, C. and Umgiesser, G.: Hydrodynamic modeling of a coastal lagoon: The Cabras lagoon in Sardinia, Italy, Ecol. Model., 188, 340-357, 2005.

Ferrarin, C., Razinkovas, A., Gulbinskas, S., Umgiesser, G., and Bliudziute L.: Hydraulic regime-based zonation scheme of the Curonian Lagoon, Hydrobiologia, 611, 133-146, 2008.

Ferrarin, C., Umgiesser, G., Bajo, M., Bellafiore, D., De Pascalis, F., Ghezzo, M., Mattassi, G., and Scroccaro I.: Hydraulic zonation of the lagoons of Marano and Grado, Italy. A modelling approach, Estuar. Coast. Shelf Sci., 87, 561-572, 2010.

Funkquist L.: A unified model system for the Baltic Sea, Elsevier Oceanography Series, 69, 516-518, doi:10.1016/S04229894(03)80082-X, 2003.

Galkus, A.: Specific Fresh and Saline Water Circulation Patterns in the Klaipeda Strait and Northern Part of Curonian Lagoon, Ann. Geogr., 40, 3-16 , 2007 (in Lithuanian).

Geyer, W. and Signell, R.: A reassessment of the role of tidal dispersion in estuaries and bays, Estuar. Coast., 15, 97-108, 1992.

Hench, J., Blanton, B., and Luettich, R.: Lateral dynamic analysis and classification of barotropic tidal inlets, Cont. Shelf Res., 22, 2615-2631, 2002.

Jia, P. and Li, M.: Dynamics of wind-driven circulation in a shallow lagoon with strong horizontal density gradient, J. Geophys. Res., 117, C05013, doi:10.1029/2011JC007475, 2012a.

Jia, P. and Li, M.: Circulation dynamics and salt balance in a lagoonal estuary, J. Geophys. Res., 117, C01003, doi:10.1029/2011JC007475, 2012b.

Jurevičius, R.: Hydrodynamic conditions in the Curonian Lagoon, in: Kursiu Marios, edited by: Jankevičius, K., Gasiunas, I., Gediminas, A., Gudelis, V., Kublickas, A., and Maniukas, I., Vilnius, 69-108, 1959 (in Russian).
Kim, C. and Park, K.: A modeling study of water and salt exchange for a micro-tidal, stratified northern Gulf of Mexico estuary, J. Marine Syst., 96-97, 103-115, 2012.

Kjerve, B. and Magill, K. E.: Geographic and hydrodynamic characteristics of shallow coastal lagoons, Mar. Geol., 88, 187-199, 1989.

Li, Y. and Li, M.: Wind-driven lateral circulation in a stratified estuary and its effects on the along-channel flow, J. Geophys. Res., 117, C09005, doi:10.1029/2011JC007829, 2012.

Luettich, R., James, L., Werner, F. E., and Brian, O.: Barotropic tidal and wind driven larval transport in the vicinity of a barrier island inlet, Fish. Oceanogr., 8, 190-209, 1999.

Luettich, R., Carr, S., Reynolds-Fleming, J., Fulcher, C., and McNinch, J.: Semi-diurnal seiching in a shallow, micro-tidal lagoonal estuary, Cont. Shelf Res., 22, 1669-1681, 2002.

Monismith, S. G.: An experimental study of the upwelling response of strati?ed reservoirs to surface shear stress, J. Fluid Mech., 171, 407-439, 1986.

Raudsepp, U. and Kouts, T.: Wind driven circulation the Curonian Lagoon, Environ. Chem. Phys., 24, 151-155, 2002.

Reyes-Hernández, C. and Valle-Levinson, A.: Wind modifications to density-driven flows in semienclosed, rotating basins, J. Phys. Oceanogr., 40, 1473-1487, 2010.

Smagorinsky, J.: General circulation experiments with the primitive equations, I. The basic experiment, Month. Weath. Rev., 91, 99152,1963

Stommel, H. and Farmer, H.: On the nature of estuarine circulation, technical report, Woods Hole Oceanogr. Inst., Woods Hole, Mass, 1952.

Umgiesser, G.: Modelling the Venice Lagoon, International Journal of Salt Lake Research, 6, 175-199, 1997.

Umgiesser, G. and Bergamasco, A.: Outline of a Primitive Equations Finite Element Model. Rapporto e Studi, Istituto Veneto di Scienze, Lettere ed Arti XII, 291-320, 1995.

Umgiesser, G., Melaku Canu, D., Cucco, A., and Solidoro, C.: A finite element model for the Venice Lagoon, Development, set up, calibration and validation, J. Marine Syst., 51, 123-145, 2004.

Unesco: The Practical Salinity Scale 1978 and the International Equation of State of Seawater 1980, Unesco technical papers in marine science 36, 25 pp., 1981.

Valle-Levinson, A.: Density-driven exchange flow in terms of the Kelvin and Ekman numbers, J. Geophys. Res., 113, C04001, doi:10.1029/2007JC004144, 2008.

Valle-Levinson, A. and Blanco, J. L.: Observations of wind influence on exchange flows in a strait of the Chilean Inland Sea, J. Mar. Res., 62, 721-741, 2004.

Valle-Levinson, A., Jara, F., Molinet, C., and Soto, D.: Observations of intratidal variability of flows over a sill/contraction combination in a Chilean fjord, J. Geophys. Res., 106, 7051-7064, 2001.

Wong, K.: The effect of coastal sea level forcing on Indian River Bay and Rehoboth Bay, Delaware, Estuar. Coast. Shelf Sc., 32, 213-229, 1991.

Zemlys, P., Ertürk, A., and Razinkovas, A.: 2-D finite element ecological model for the Curonian Lagoon, Hydrobiologia, 611, 167-179, 2008. 